Article

\title{
Shifts in Climate-Growth Relationships of Sky Island Pines
}

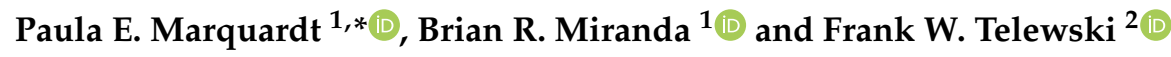 \\ 1 USDA Forest Service, Northern Research Station, 5985 Highway K, Rhinelander, WI 54501, USA; \\ brian.r.miranda@usda.gov \\ 2 W.J. Beal Botanical Garden, Department of Plant Biology, Michigan State University, East Lansing, \\ MI 48824, USA; telewski@msu.edu \\ * Correspondence: paula.marquardt@usda.gov
}

Received: 27 September 2019; Accepted: 30 October 2019; Published: 12 November 2019

check for updates

\begin{abstract}
Rising temperatures and changes in precipitation may affect plant responses, and mountainous regions in particular are sensitive to the impacts of climate change. The Santa Catalina Mountains, near Tucson, Arizona, USA, are among the best known Madrean Sky Islands, which are defined by pine-oak forests. We compared the sensitivity and temporal stability of climate-growth relationships to quantify the growth responses of sympatric taxa of ponderosa pine to changing climate. Three taxa (three-needle, mixed-needle, and five-needle types) collected from southern slopes of two contact zones (Mt. Lemmon, Mt. Bigelow) were evaluated. Positive climate-growth correlations in these semiarid high-elevation pine forests indicated a seasonal shift from summer- to spring-dominant precipitation since 1950, which is a critical time for reproduction. Mixed- and five-needle types responded to winter precipitation, and growth was reduced for the five-needle type when spring conditions were dry. Growth trends in response to temperature and specific to site were observed, which indicated the climate signal can be weakened when data are combined into a single chronology. Significant fluctuations in temperature-growth correlations since 1950 occurred for all needle types. These results demonstrated a dramatic shift in sensitivity of annual tree growth to the seasonality of the limiting factor, and a climatic trend that increases local moisture stress may impact the stability of climate-growth relationships. Moreover, output from temperature-growth analyses based on ring-width data (for example from semiarid sites) that does not account for positive and negative growth trends may be adversely affected, potentially impacting climate reconstructions.
\end{abstract}

Keywords: dendrochronology; ecology; moving window analysis; Pinaceae; Pinus arizonica Engelm.; Pinus ponderosa var. brachyptera (Engelm.); Ponderosae; response function; tree rings

\section{Introduction}

The Madrean Sky Islands are rugged mountain ranges isolated by desert that signify natural ecological laboratories [1]. The steep rocky terrain offers opportunities to study biological populations across varied microclimate gradients and landscapes. Tree growth at the ecotone between communities is particularly susceptible to varying climate because small changes in the environment may have a large impact on annual growth $[2,3]$. In the Western United States, the consequences of rising temperatures and seasonal shifts toward earlier onset of spring (i.e., warmer temperatures) and reduced snowpack are being observed at high elevations, and these trends in shifting climate are expected to increase the length of hydrological drought by the end of the century [4].

The Sky Islands of Southeastern Arizona include the well-known Santa Catalina Mountains, which contain a habitat suitable for stands of ponderosa pine that include three morphological variants 
representing two distinct species [5,6]. At high elevation, two species co-occur, Pinus arizonica Engelm. and the closely related P. ponderosa Lawson \& Lawson var. brachyptera (Engelm.) Lemmon. The latter species is also known as Taxon $X$, and the taxa are clearly distinguishable by needle traits with high heritability [5-8]. P. ponderosa var. brachyptera exists in two forms, a nearly pure three-needle type that survives at the highest altitudes on southern slopes (2300-3000 m), northern slopes, and cold air drainages, and a mixed-needle type that is interspersed with the three-needle type at transition zones. $P$. arizonica is a five-needle type found at lower elevations (below $2600 \mathrm{~m}$ ). Thus, the five-needle pine is more successful at warmer and drier, lower elevations, whereas the three-needle pine survives at colder and wetter, higher elevations. On steep southern slopes the sharp transition of species occurs over just c.130 m slope distance [6,9].

We combined our dataset with Hal Fritts' Mt. Bigelow chronologies [10-12], part of an earlier meta-analysis which consisted of the three co-occurring taxa (three-needle, mixed-needle, and five-needle types) sampled across a narrow climate gradient. We sampled the same population c. 50 years later for a comparative analysis of similar aged cohorts, and also sampled the less dry Mt. Lemmon location to determine the effect of site conditions on growth responses. Our goal was to determine whether the climate-growth relationships have changed over the last century. Shifting seasonality or relationships with limiting factors would have implications for reliably predicting the vulnerability of tree species and needle types to climate change, conservation management, and climate reconstruction.

Previously, we reported on the two species of ponderosa pine displaying different growth responses to moisture stress that varied based on the microsite environment [13]. P. arizonica's growth was reduced for longer periods by drought than P. ponderosa var. brachyptera, and the climatic response was greater at the site with higher soil moisture content (Mt. Lemmon). Since the turn of the twentieth century, average temperatures have been steadily increasing globally [14], and regionally (Figure 1). Because rising temperatures, variable precipitation (Figure 1) and predicted shifts in the monsoon season will influence weather patterns and drought in the Southwestern United States [15], we hypothesized that the seasonality of limiting factors will change over time. The objective of the study was to compare the correlations of ring widths with temperature and precipitation to assess shifts in the seasonality of climate-growth responses. 


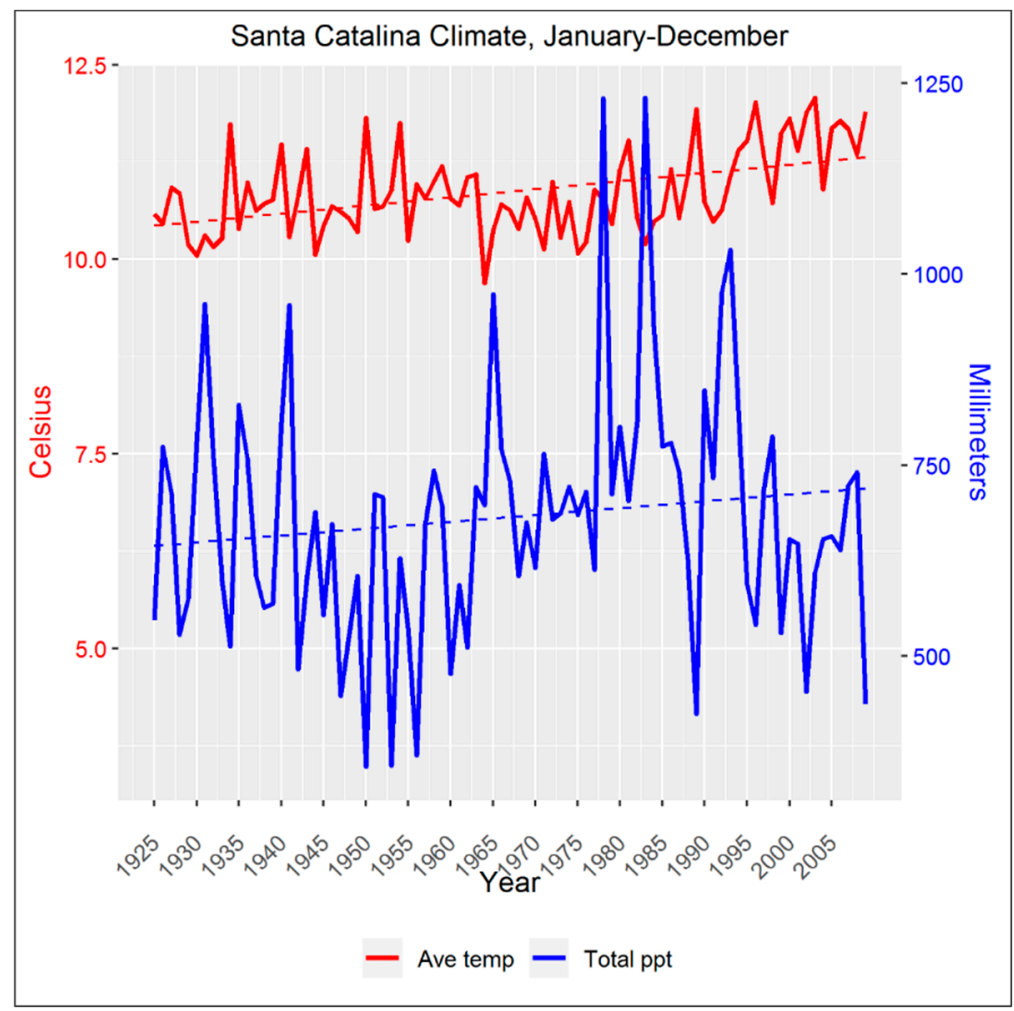

Figure 1. Climate diagram for the Santa Catalina Mountains, for the 84-year reference period spanning 1925-2009 for average annual temperature (Ave temp, ${ }^{\circ} \mathrm{C}$; red line) and total annual precipitation (Total ppt, mm; blue line), respectively. The Ave temp increased by $1.3^{\circ} \mathrm{C}$ over the course of the data set (from $10.6{ }^{\circ} \mathrm{C}$ to $11.9^{\circ} \mathrm{C}$ ). The dotted lines are the linear trend lines. Site-specific climatic data sets [Mt. Lemmon (MTL), Mt. Bigelow (BIG)] [13,16] were validated with local climate data [13], and averaged to construct this diagram.

\section{Materials and Methods}

\subsection{Study Area}

Tree-ring cores were sampled from two rugged southern slopes in the Santa Catalina Mountains located $28 \mathrm{~km}$ northeast of Tucson, AZ, USA: Mt. Lemmon (MTL) and Mt. Bigelow (BIG; Figure 2). $\operatorname{BIG}(32.41,-110.71,2534 \mathrm{~m}$ a.s.l.) is drier than $\operatorname{MTL}(32.43,-110.79,2577 \mathrm{~m}$ a.s.l.), with average available water-holding capacities of $3.8 \%$ and $9.2 \%$, respectively [13]. The climate of the desert southwest is semiarid and warm with two rainy seasons, the summer monsoons (July through September) and winter cyclones (November through March) each delivering up to half of the annual precipitation to the region [17]. P. arizonica, and P. ponderosa var. brachyptera (consisting of two-needle types described below) are dominant species in the mixed conifer forest. We selected archived samples from transition zones where the three different needle types all grew together, which included the lower and upper moisture availability limits for P. ponderosa var. brachyptera and P. arizonica, respectively. 


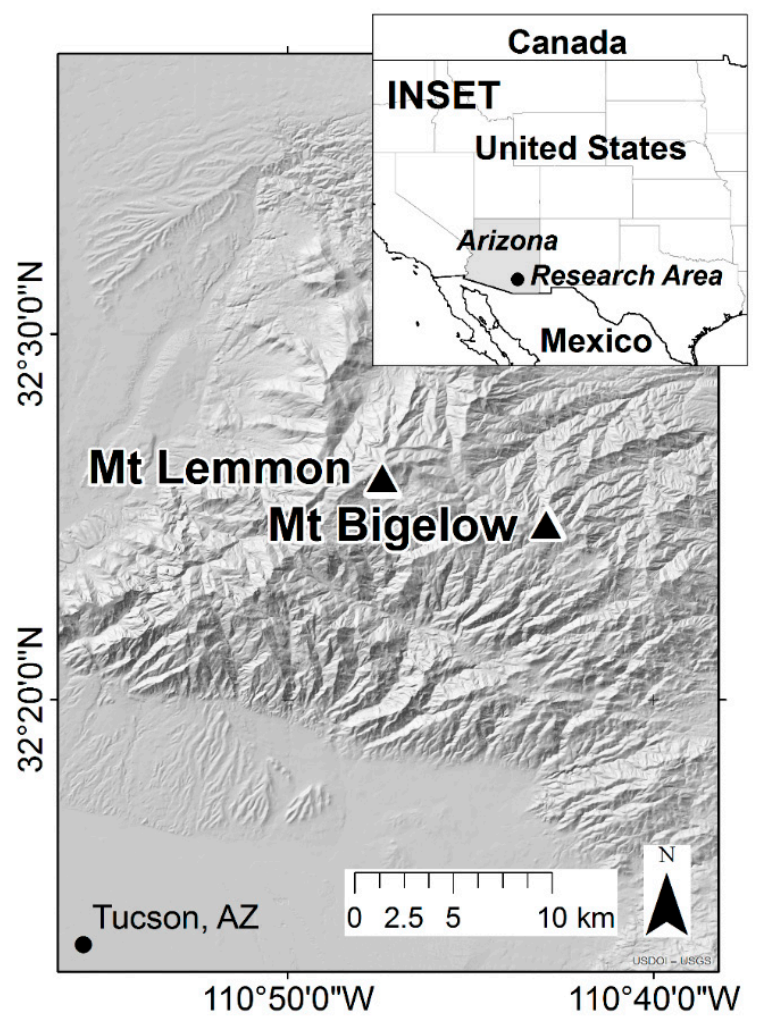

Figure 2. Locations of the two populations sampled for growth analysis: Mt. Lemmon (MTL) and Mt. Bigelow (BIG). Black symbols locate study plots northeast of Tucson, AZ where three-needle, mixed-needle, and five-needle pines are sympatric.

\subsection{Climate Data}

The local meteorological stations provided only short but accurate climate records; thus, specific high-resolution gridded climate $(1 \mathrm{~km})$ datasets were developed using the ANUSPLIN package $[16,18]$. Climate dataset development and validation were described earlier [13]. Climatic variables were summarized to monthly values of average temperature (TAVG), average minimum temperature (TMIN), and total precipitation (PCP) because they were previously found to be significant drivers of growth responses [13].

\subsection{Tree Growth Chronologies and Data Archives}

We obtained tree-ring widths for P. arizonica [chronology (crn) 651000] and P. ponderosa var. brachyptera (three-needle type, crn 631000; and mixed-needle type, crn 641000), located at $2500 \mathrm{~m}$ in elevation on south-facing slopes, from the Laboratory of Tree-Ring Research (LTRR, Tucson, AZ, USA; Table S1; Figure S1). These early period (E) data (1881-1960) from BIG were acquired as three composite chronologies that had been standardized with a negative exponential curve and converted to unit-less ring-width indices (RWI) [10-12] then trimmed to 1891-1949 for E analysis. Archived samples were not available from MTL for an early period analysis.

In addition, we developed six new composite chronologies (three from BIG, three from MTL) from raw ring widths archived with the International Tree-Ring Data Bank (ITRDB; Table S1, Figures S2 and S3) [19]. The recent period ( $R$; 1950-2007) raw chronologies did not overlap (in time scale) with early period to simplify the response, and were de-trended using a modified negative exponential curve to remove juvenile and geometric age trends, then converted to standardized ring-width indices using the ARSTAN program [20]. The mean chronologies [computed by ARSTAN (Tucson, AZ, USA) or acquired from the LTRR] were visualized by using plotting functions in the dplR package [21,22] for $\mathrm{R}[23]$. 
The objective of this study was to compare the recent period tree-ring data with the analysis conducted c. 50 years ago by Fritts [11,12], while using the same age of trees for the analysis. Expressed Population Signal (EPS) measures the common variability of a composite chronology and for early period was c. 0.89-0.96, indicating a strong common signal (see Appendix A for EPS thresholds). The recent chronologies comprised of a minimum of six trees of each needle type (EPS 0.82-0.90) were selected from the larger archived dataset [19]. Trees were characterized by average needle number per fascicle (Table 1) reported for the selected individuals [13]. Trees that averaged $>4.6$ needles per fascicle were designated P. arizonica [24], and P. ponderosa var. brachyptera contained two taxa identified as a mixed-needle tree $(3.2 \leq$ mean $\leq 4.6$ needles per fascicle), and a three-needle tree $(<3.2$ needles per fascicle) $[5,9,25]$.

Table 1. Average needle counts for trees sampled for tree-ring correlation analyses at two sites: Mt. Lemmon (MTL) and Mt. Bigelow (BIG). Three taxa were sampled: Pinus ponderosa var. brachyptera [three (3)-needle type], Pinus ponderosa var. brachyptera [mixed (M)-needle type], and Pinus arizonica [five (5)-needle type].

\begin{tabular}{cccccc}
\hline Site. & Taxa & Ave (\#) & Range & SD & N \\
\hline BIG & 3 & 3.1 & $3.0-3.1$ & 0.1 & 7 \\
MTL & 3 & 3.1 & $3.0-3.2$ & 0.1 & 7 \\
BIG & M & 3.7 & $3.2-4.6$ & 0.6 & 6 \\
MTL & M & 3.8 & $3.4-4.6$ & 0.5 & 7 \\
BIG & 5 & 4.9 & $4.8-5.0$ & 0.1 & 7 \\
MTL & 5 & 4.9 & $4.9-5.0$ & 0.0 & 6
\end{tabular}

Ave (\#): grand mean of average needle number per fascicle; Range: difference between the highest and lowest Ave (\#); SD: standard deviation of Ave (\#), N: number of trees sampled.

\subsection{Climate-Growth Relationships}

Our first analysis of climatic influence on tree-ring growth examined the correlations between climatic variables and ring-width index values using multivariate estimates obtained from the principal component regression model [12]. We used the relationship between local climatic variables and inter-annual growth to determine the differences in seasonal growth responses. We analyzed the response function correlations similarly to Marquardt et al. (2019) [13], with modifications. The analysis was conducted with standard ARSTAN chronologies, PCP, and TMIN climate variables, and needle type was the subject of analysis, with chronologies separated into two time periods: early period (E) and recent period (R). Analyses computed bootstrapped response functions using the treeclim package [26] at three site $\times$ period combinations (BIG-E, BIG-R, MTL-R). Eight seasonal climatic variables (four PCP and four TMIN) were partitioned to quantify precipitation and temperature effects during times relevant for tree growth in our study areas. Seasonal variables were derived by combining the monthly data into two rainy seasons consisting of three and five months, respectively: summer (July-September) and winter (November-March), separated by three months of arid spring (April-June). October is a transition month between the two monsoon seasons and is not included in the analysis. For specific seasons with significant response function values $(p<0.05)$, those values lying above the axis show a positive response between tree-ring width and climatic variables, and values lying below the axis show a negative response. To examine the impact (on growth) from winter precipitation, we examined one dry winter in 1961, and one normal moisture winter in 1962 across both sites, which had similar mean series lengths [13]. We used the percent difference of ring width indices to quantify the growth variability between years with contrasting moisture conditions.

To evaluate the temporal stability of climate-growth relationships, we compared climate data and composite chronologies using a univariate moving window correlation analysis within the treeclim package for $\mathrm{R}$ using the 'dcc' function [26]. The 18-month dendroclimatic window was set from April (previous year) to September (current year) with a 30-year moving interval and 5-year offset. Two climate variables were considered separately for analysis. Total precipitation (PCP) and average 
temperature (TAVG) were divided into four seasons of three months each: winter (January-March), spring (April-June), summer (July-September), and fall (October-December). The previous summer and fall seasons were also considered, which increased the number of seasons analyzed to six. Temporal instability of the moving correlation functions was tested with G-test to determine which time series fluctuations were significantly different from those of a random time series [26]. The treeclim results of the moving window analyses were plotted using functions in the 'corrplot' package [27] for R.

\section{Results}

\subsection{Seasonal Climate-Growth Relationships}

Current spring PCP was the strongest predictor of tree growth for all needle types for BIG-R (average $r=0.27 \pm 0.04$ ) and MTL-R (average $r=0.36 \pm 0.04$ ) after 1950. The strongest growth responses were positive, producing significant correlations with spring PCP for all needle types at both sites for the recent period (Table 2). In contrast, significant positive PCP-growth correlations were observed in summer rather than spring for BIG-E for all needle-types (average $r=0.29 \pm 0.03$; Table 2). The response function analysis (independent of period and location) indicated that $67 \%$ (4 out of 6 ) of mixed-and five-needle type populations recorded a significant climate signal during winter prior to the growing season (Table 2). For the two periods, significant positive PCP-growth correlations in winter were observed only for BIG-E (average $r=0.24 \pm 0.04$ ) and at MTL-R (average $r=0.33 \pm 0.03$ ) and only for mixed- and five-needle types. Winter precipitation was averaged between sites for two years with contrasting moisture patterns. The winter of 1961 was one of the driest on record (137.2 mm), but the following year (1962) was of normal moisture conditions (319.43mm). Considering mean ring-width indices, growth for the five-needle type was 41\% greater on average in 1962 than in 1961 (Table 3). A smaller increase in growth occurred for the three-needle type (26\%) and mixed-needle type (19\%).

Table 2. Seasonal precipitation-growth relationships were determined by principal components multiple regression for three taxa [three-needle (3N), mixed-needle (MN), five-needle $(5 \mathrm{~N})$ ] growing at two transition zones [Mt. Bigelow (BIG), (Mt. Lemmon (MTL)] within the Santa Catalina Mountains.

\begin{tabular}{|c|c|c|c|c|c|c|c|c|c|c|c|c|}
\hline \multirow{3}{*}{ Taxa } & \multicolumn{4}{|c|}{ Early } & \multicolumn{4}{|c|}{ Recent } & \multicolumn{4}{|c|}{ Recent } \\
\hline & \multicolumn{4}{|c|}{ BIG (1891-1949) $2500 \mathrm{~m}$} & \multicolumn{4}{|c|}{ BIG (1950-2007) 2534 m } & \multicolumn{4}{|c|}{ MTL (1950-2007) 2577 m } \\
\hline & PrSum & Win & Spr & Sum & PrSum & Win & Spr & Sum & PrSum & Win & Spr & Sum \\
\hline $3 \mathrm{~N}$ & - & - & - & 0.32 & - & - & 0.32 & - & - & - & 0.32 & - \\
\hline $\mathrm{MN}$ & - & 0.26 & - & 0.29 & - & - & 0.26 & - & - & 0.35 & 0.38 & - \\
\hline $5 \mathrm{~N}$ & - & 0.21 & - & 0.26 & - & - & 0.24 & - & - & 0.31 & 0.39 & - \\
\hline
\end{tabular}

PrSum = previous summer (July-September); Win = winter (November-March); Spr = spring (April-June); Sum = summer (July-September). The standard index composite chronologies analyzed were BIG-E for the early $(\mathrm{E})$ period of 1891-1949, and BIG-R and MTL-R for the recent (R) period of 1950-2007. Only significant correlations are reported. All coefficients and confidence intervals are reported in Table S2. 
Table 3. Average (AVE) and standard deviation (SD) of mean ring-width indices and percent difference (\% DIFF) in growth between one dry winter (1961) and one normal winter (1962) for three-needle, mixed-needle, and five-needle types at two transition zones [Mt. Bigelow (BIG), (Mt. Lemmon (MTL)] within the Santa Catalina Mountains.

\begin{tabular}{cccccc}
\hline Three-Needle Type & \multicolumn{1}{c}{} \\
\hline Year & BIG-R & MTL-R & AVE & SD & \% DIFF \\
1961 & 731 & 769 & 750.0 & 026.9 & \\
1962 & 1000 & 886 & 943.0 & 080.6 & 26 \\
\hline Mixed-Needle Type & & & & \\
\hline Year & BIG-R & MTL-R & AVE & SD & \% DIFF \\
1961 & 832 & 673 & 752.5 & 112.4 & \\
1962 & 967 & 828 & 897.5 & 098.3 & 19 \\
\hline Five-Needle Type & & & & & \\
\hline Year & BIG-R & MTL-R & AVE & SD & $\%$ DIFF \\
1961 & 716 & 627 & 671.5 & 062.9 & \\
1962 & 966 & 898 & 932.0 & 048.1 & 41 \\
\hline
\end{tabular}

Growth data for each needle type were obtained from standardized chronologies developed for recent $(\mathrm{R})$ period tree-ring correlation analyses.

\subsection{Temporal Stability of Climate-Growth Relationships}

The PCP-growth relationships were stable; the G-tests for PCP are non-significant $(p>0.05)$ for all needle types analyzed across sites and periods (BIG-E; BIG-R; MTL-R; data not shown). Because these correlation results supported the response function analysis reported above, we have only shown data for the PCP response function analysis.

The TAVG-growth relationship was stable from 1895-1949 for BIG-E across needle types (i.e., G-test $p$-values $>0.05$; Figure 3A). The season with the largest number of individual significant negative correlations (c. $<-0.4 ; \alpha=0.05$ ) was PrSum(April-June; i.e., summer of the previous year) with 4-6 correlations (out of 6), followed by Summer with 2-5 correlations (out of 6). In contrast, the relationship between TAVG and growth became unstable during the recent period from 1960 to 2004 ( $p \leq 0.05$; Figure 3B,C). This instability was indicated by significant G-tests (denoted by \#), and changes in sign for seasonal TAVG-growth correlations, from negative to positive for PrSum for BIG-R (Figure 3B) and from positive to negative for PrevFall (July-September; i.e., fall of the previous year) at MTL-R (Figure 3C) across all three needle types. For BIG-R, the fall season had the greatest frequency of significant positive correlations (c. $>0.4 ; \alpha=0.05$ ) with 5-6 correlations (out of 6 ). In comparison, the growth of MTL-R trees experienced mostly negative correlations with TAVG. The season with the largest number of significant negative correlations $(c .<-0.4 ; \alpha=0.05)$ was winter with $1-2$ correlations (out of 6) for all needle types. 

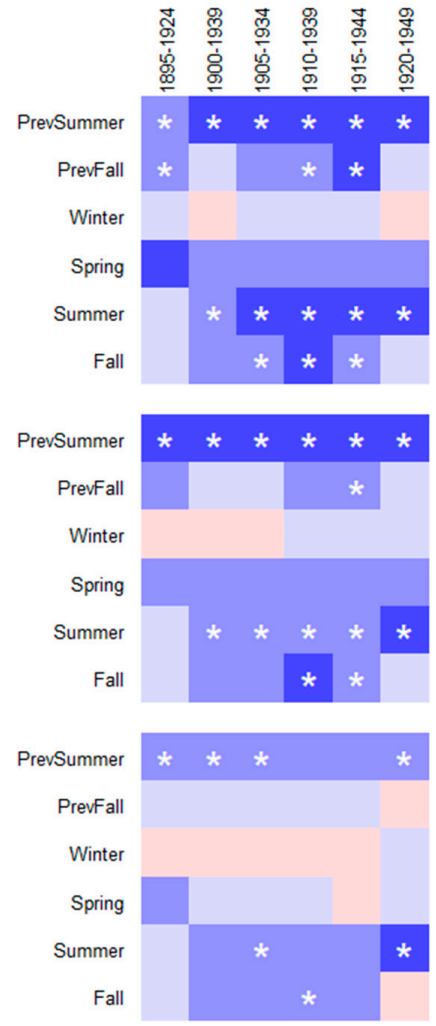

(A)BIG-E
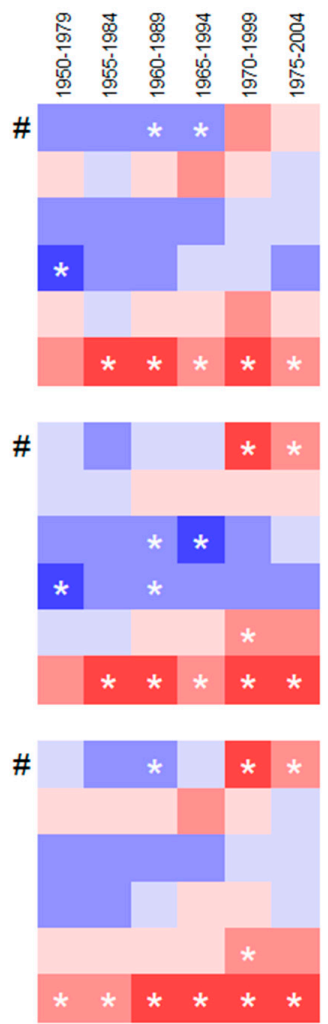

(B) BIG-R

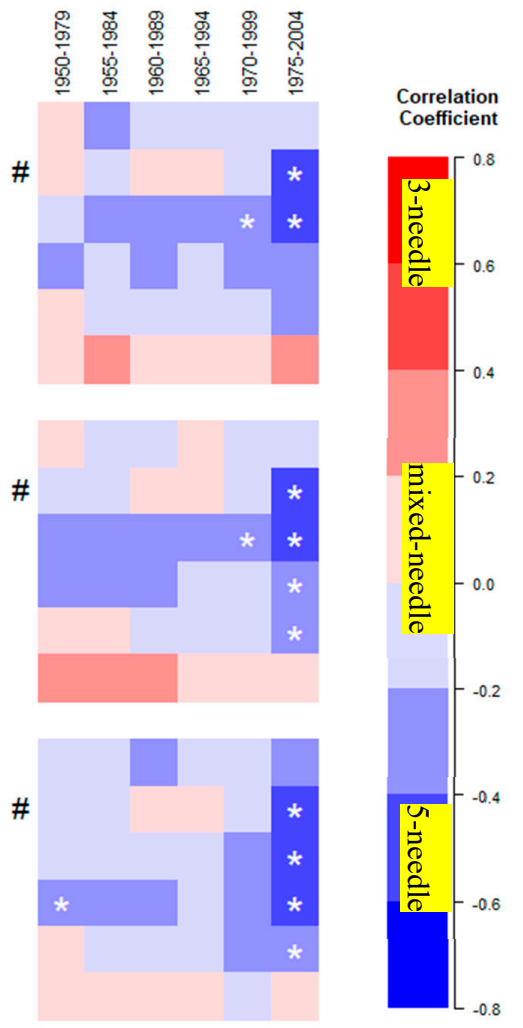

(C) MTL-R

Figure 3. Moving window correlation coefficients for seasonal average temperature (TAVG)-growth relationships for three different needle types, across two time periods (Early (E), Recent (R)) at two transition zones within the Santa Catalina Mountains. From top to bottom are correlations for three-needle, mixed-needle, and five-needle types, with columns $(\mathbf{A}-\mathbf{C})$ designating site and time period. Color scale $=$ correlation coefficients; significant correlations $(p<0.05)$ are denoted by * Intervals with low correlations $(c .+0.2)$ are shaded pale red or pale blue, with the color intensity increasing with correlation strength. Within time periods significant G-tests are denoted by \#, which indicates significant variability in the TAVG growth relationship over the time period (i.e., a sign of temporal instability). Seasons fall along the $y$-axis, which are defined as PrSum $=($ April-June), PrevFall $=$ (July-September), Winter = (October-December $),$ Spring $=($ January-March $)$, Summer $=($ April-June $)$, and Fall $=($ July-September $)$. The standard index was used in the growth analyses. Confidence intervals are reported in Table S3.

\section{Discussion}

\subsection{Seasonal Climate-Growth Relationships}

Our chronology analysis highlighted a dramatic shift in annual growth in response to climatic changes since the late 1950s [28]. Early period Mt. Bigelow ring widths correlated most strongly with summer precipitation, indicating moisture conditions were sufficient for stomatal conductance and annual growth to occur during the entire summer season [29], thus maximizing biomass production. In comparison, recent climate-growth relationships were cool season correlations that occur when trees restrict their wood production to early spring while conditions are favorable for growth at dry sites [12,29] Thus, our recent season data indicated spring precipitation was the most important variable for tree growth, which is also a crucial time for the formation of male and female reproductive structures. These results support our hypothesis that the seasonality of climate variables important to annual growth has shifted over time. We also found that winter precipitation was correlated with the 
growth of mixed- and five-needle types, but not with growth of the three-needle type, suggesting the three taxa have different ecological requirements for growth at their contact zone.

We report important fundamental differences within and between species in seasonal response to climate, which suggest that adaptation of tree species to length of growing season may have occurred. These results support the influence of historical precipitation patterns and climate restrictions for different taxa $[30,31]$. The length of growing season of P. ponderosa in Nevada was controlled entirely by moisture conditions and not temperature by monitoring the cambial activity for two consecutive years with contrasting moisture, one wet winter and one dry spring [32]. Summer precipitation was not used by the trees unless the start of the growing season was delayed by dry winter and/or spring conditions. Because moisture availability determines the length of growing season for all needle types of ponderosa pine studied in the Santa Catalina Mountains [13], we hypothesize that one taxon may optimize growth over a shorter or longer growing season (five-needle, three-needle, respectively) [10], and a third taxon may grow best under a variable growing season (mixed-needle), which we call the dry cool-season hypothesis.

In support of this dry cool-season hypothesis, cambial activity was measured during the dry 1961 growing season [10]; the average Palmer Drought Severity Index (PDSI), a measure of soil moisture availability [33], was c. -3.0 [13]. [More negative values of PDSI indicate drought stress and range from -4 to +4 ]. The cambial expansion of P. ponderosa var. brachyptera (the three- and mixed-needle types) initiated under dry winter conditions in February, followed by the five-needle type (P. arizonica) six weeks later in April. Cambial growth occurred for all needle types during the summer, and cessation of growth coincided in September. All needle types co-existed at the Mt. Bigelow transition zone ( $2500 \mathrm{~m}$ a.s.l.) including trees that were analyzed for climatic response in this study and the prior study [11]. Although the initiation of radial growth for the following normal moisture year (average PDSI c. -0.5) [13] was not determined, we can predict the growth response of the five-needle type to wet winter conditions from the recent literature on moisture driven cambial activity described above [32]. Because the five-needle type responds positively to winter precipitation, the taxon should initiate growth earlier. Further support was provided by our chronology data, which showed that growth for the five-needle type is robust when winter moisture conditions are normal (compared to dry winter). Also, a 15-22\% increase in growth for the five-needle type was observed above that for the three- and mixed-needle types, respectively, for normal moisture winter. This increase in growth is suggestive that five-needle type starts cambial expansion earlier in wet springs than dry springs and supports our earlier study [13] that found the five-needle pine responded positively to PDSI for longer periods of time. Long correlation with PDSI suggests a possible adaptation to drought under a mechanism that 5-needle trees grow only when there is a reliable water source. Therefore, our study results reinforce that moisture availability determines the length of growing season of ponderosa pine, and that some needle types may display variability in the timing of xylogenesis [32].

\subsection{Temporal Stability of Climate-Growth Relationships}

We found opposing growth trends in response to temperature after 1950 between the two sites, which indicates that combining tree-ring data from multiple sites into a single chronology can dilute the individual climate signals. Opposing temperature-growth trends were first reported in white spruce stands occurring at the tree-line in two mountain ranges sampled across Alaska, and that temperature explained more variability in annual tree growth post-1950 [34]. These regional Alaskan forests are composed of individual trees growing in heterogeneous environments where temperature thresholds operate, influencing tree biology and the response to limiting factors that appears in the final chronology. Our report extends these tree-line studies to semiarid regions where precipitation rather than temperature is the factor most limiting to tree annual growth. Nonetheless, we also observed a significant shift from positive to negative growth correlations with temperature under less dry conditions for five-needle and mixed-needle types during cool seasons, which is indicative of temperature-induced drought stress [34], or growing season respiration [13] limiting the ponderosa 
pine annual growth. In comparison, at the drier site we observed a shift from negative to positive temperature correlations during PrSum season post-1950, indicating reduced water stress. Furthermore, if unaccounted for, these opposing trends to temperature are weakening the warming climate signal (post-1950) by combining positive and negative growth responses that adversely affect growth response analyses and by extension climate reconstructions based on ring-width data, even in dry environments where precipitation is growth limiting.

Also, by extending our analysis to include the fall season, we observed that growth in individual trees is positively and significantly correlated to temperature. These results suggest that all needle types may respond positively to a range of temperature increases late in the season at the contact zone of dry habitats. However, an extended growing season most likely will be determined by moisture availability and not rising temperatures, as recently described for P. ponderosa, a closely related species [32].

\section{Conclusions}

A temporal shift in limiting factor indicated spring is the most important growing season for recent period; thus, the three taxa that responded to summer precipitation pre-1950 are now responding to spring precipitation post-1950. This shift in limiting factor represents a shift in allocation of tree resources from maximizing biomass (summer) to reproduction (spring), a critical time for tree phenology and the formation of male and female reproductive structures. Five- and mixed-needle types correlated positively to winter precipitation, suggesting soil moisture was controlling the length of growing season. Also, we found significant fluctuations in temperature-growth correlations during recent period for all needle types. Thus, a shift in limiting factor that impacts the growth sensitivity of trees, such as warming trends that increase local moisture stress, may also impact the stability of climate-growth relationships, and if unaccounted for, obscures the use of tree-rings to analyze temperature-growth responses and reconstruct climate on moisture-limited sites.

Supplementary Materials: The following are available online at http://www.mdpi.com/1999-4907/10/11/1011/s1, Table S1: Ponderosa pine tree-ring data archives, Table S2: Coefficients and confidence intervals for Table 2's response function seasonal precipitation-growth analysis, Table S3: Coefficients and confidence intervals for Figure 3's moving window seasonal TAVG growth analysis, Figure S1: Average yearly standard chronology for three-needle, mixed-needle, and five-needle types in the early BIG tree-ring study [10,11], Figure S2: Average yearly standard chronologies for three-needle, mixed-needle, and five-needle types in the recent BIG tree-ring study, Figure S3: Average yearly standard chronologies for three-needle, mixed-needle, and five-needle types in the recent MTL tree-ring study.

Author Contributions: P.E.M. conceived the study, designed the experiments, and analyzed data; B.R.M. assisted with data analysis; F.W.T. contacted the LTRR to obtain historical tree-ring data files; P.E.M. wrote the paper; F.W.T. and B.R.M. edited the paper.

Funding: The USDA Forest Service, Northern Research Station, and the Department of Plant Biology, Michigan State University provided financial support for this research project.

Acknowledgments: This paper is part of a dissertation submitted to Michigan State University in partial fulfillment of requirements for a Doctor of Philosophy degree. We thank the following people for help on the project: M. Munro and C. Baisan supplied H. Fritts' chronology samples. J. Stanovick provided statistical support. H. Jenson provided GIS support. D. Donner reviewed the paper.

Conflicts of Interest: The authors declare no conflict of interest.

\section{Appendix A}

\section{Defining Chronology Confidence and EPS Thresholds}

Analysis of variance (ANOVA) and correlation-derived estimates of population parameters require a minimum of five single-core series and 30-annual rings to provide accurate values for tree-ring statistical analysis [35]. Therefore, we selected 6-7 trees (two or more cores per tree), setting a minimum length limit of a 47-year common interval to construct composite chronologies for each group of trees (Table S1; Figures S2 and S3). The percent variance component for the group chronology VC(Y) as determined by analysis of variance is equivalent to the between tree correlation $\bar{r}_{b t}$ of correlation 
tree-ring analysis [35,36]. $\bar{R}_{b t}$ measures the common signal strength and is dependent on sample depth [37]. Expressed Population Signal (EPS) is a measure of statistical quality to help produce a reliable population level estimate of the climate signal, and is dependent on $\bar{r}_{b t}$ [35]

$$
E P S=\frac{t \bar{r}_{b t}}{t x \bar{r}_{b t}+\left(1-\bar{r}_{b t}\right)}
$$

Although the minimum EPS value of 0.85 is recommended by Wigley et al. [36] to be routinely applied in dendrochronological analyses, we considered EPS values ranging from 0.82 to 0.90 for each group of trees that included growth data from 1950 to 2007, which is a good reflection of overall chronology confidence. Given that our study design includes a variable core depth, this method of estimating the common chronology signal with a range of EPS values was simpler to apply. The chronology signal describes the variance in common to all tree-ring series sampled and analyzed at a specific site. This approach of using a range of EPS values was supported by Briffa and Jones' [34] suggestion that a minimum value may not represent the most appropriate estimate of chronology confidence for all situations. For example, a 3\% reduction in EPS from 0.85 to 0.82 would signify a reduction of $2 \%$ in explained climate variance. Thus, for climate-growth relationships with $64-65 \%$ of variance attributed to climate, as reported by Fritts [11] for the mixed- and three-needle types of Ponderosae on Mt. Bigelow, an EPS threshold of 0.85 would have reduced the explained climate variance to $55 \%(64.5 \% \times 0.85)$. In comparison, an EPS threshold of 0.82 would have reduced the explained variance to $53 \%$. Therefore, the additional chronology error would have restricted the explained climate variance by just $2 \%$. Thus, it seems unlikely that an additional $3 \%$ reduction in chronology confidence (from 0.85 to 0.82 ) would affect the estimation of the climate signal within needle types of standardized chronologies, when sensitivities to climate are expected to be high, as in this study $[10,11,13,36]$.

The EPS thresholds for Fritts' [11] study can be estimated from formulas described by Wigley et al. [37] as:

$$
\begin{aligned}
& S N R=\frac{[N(\% Y)]}{100-\% Y} \\
& E P S=\frac{S N R}{1+S N R}
\end{aligned}
$$

where SNR is the signal to noise ratio, $\mathrm{N}$ is the number of series, and $\% \mathrm{Y}$ is the percent common variance [35]. As an example, when substituting 12 for $\mathrm{N}$ and 41 for \%Y [11] (\%EMS, from Table 1), we derived SNR $=8.4$ and EPS $=0.89$ for the five-needle type of the prior Mt. Bigelow study. Similarly, for the three-needle type, by substituting 65 for \%Y [11] we derive an EPS value of 0.96 . These values approximate EPS of the current study, as 11 years of data were removed (1950 to 1960) from the chronologies used for the early period analysis (BIG-E).

\section{References}

1. Warshall, P. The Madrean sky island archipelago: A planetary overview. In Biodiversity and Management of the Madrean Archipelago: The Sky Islands of Southwestern United States and Northwestern Mexico; DeBano, L.F., Ffolliott, P.F., Ortega-Rubio, A., Gottfried, G.J., Hamre, R.H., Edminster, C.B., Eds.; US Department of Agriculture: Fort Collins, CO, USA, 1995; pp. 6-18. [CrossRef]

2. Jump, A.S.; Hunt, J.M.; Penuelas, J. Rapid climate change-related growth decline at the southern range edge of Fagus sylvatica. Glob. Chang. Biol. 2006, 12, 2163-2174. [CrossRef]

3. Tegel, W.; Seim, A.; Hakelberg, D.; Hoffmann, S.; Panev, M.; Westphal, T.; Büntgen, U. A recent growth increase of European beech (Fagus sylvatica L.) at its Mediterranean distribution limit contradicts drought stress. Eur. J. Forest Res. 2014, 133, 61-71. [CrossRef]

4. USGCRP. Climate Science Special Report: Fourth National Climate Assessment; Wuebbles, D.J., Fahey, D.W., Hibbard, K.A., Dokken, D.J., Stewart, B.C., Maycock, T.K., Eds.; U.S. Global Change Research Program: Washington, DC, USA, 2017; Volume 1, p. 470. [CrossRef] 
5. Rehfeldt, G.E. Systematics and genetic structure of Ponderosae taxa (Pinaceae) inhabiting the Mountain Islands of the Southwest. Am. J. Bot. 1999, 86, 741-752. [CrossRef] [PubMed]

6. Epperson, B.K.; Telewski, F.W.; Willyard, A. Chloroplast diversity in a putative hybrid swarm of Ponderosae (Pinaceae). Am. J. Bot. 2009, 96, 707-712. [CrossRef] [PubMed]

7. Willyard, A.; Gernandt, D.S.; Potter, K.; Hipkins, V.; Marquardt, P.; Mahalovich, M.F.; Langer, S.K.; Telewski, F.W.; Cooper, B.; Douglas, C.; et al. Pinus ponderosa: A checkered past obscured four species. Am. J. Bot. 2017, 104, 161-181. [CrossRef] [PubMed]

8. Rehfeldt, G.E. Early selection in Pinus ponderosa: Compromises between growth potential and growth rhythm in developing breeding strategies. Forest Sci. 1992, 38, 661-677. [CrossRef]

9. Epperson, B.K.; Telewski, F.W.; Plovanich-Jones, A.E.; Grimes, J.E. Clinal differentiation and putative hybridization in a contact zone of Pinus ponderosa and P. arizonica (Pinaceae). Am. J. Bot. 2001, 88, 1052-1057. [CrossRef] [PubMed]

10. Dodge, R.A. Investigations into the Ecological Relationships of Ponderosa Pine in Southeast Arizona. Ph.D. Thesis, University of Arizona, Tucson, AZ, USA, 1963.

11. Fritts, H.C. Computer programs for tree-ring research. Tree-Ring Bull. 1963, 25, 2-7.

12. Fritts, H.C. Relationships of ring widths in arid-site conifers to variations in monthly temperature and precipitation. Ecol. Monogr. 1974, 44, 411-440. [CrossRef]

13. Marquardt, P.E.; Miranda, B.R.; Jennings, S.; Thurston, G.; Telewski, F.W. Variable climate response differentiates growth of the Sky Island ponderosa pines. Trees 2019, 3, 317-332. [CrossRef]

14. IPCC. 2007: Climate Change. The physical science basis. In Contribution of Working Group I to the Fourth Assessment Report of the Intergovernmental Panel on Climate Change; Solomon, S., Qin, D., Manning, M., Chen, Z., Marquis, M., Averyt, K.B., Tignor, M., Miller, H.L., Eds.; Cambridge University Press: Cambridge, UK; New York, NY, USA, 2007.

15. Pascale, S.; Boos, W.R.; Bordoni, S.; Delworth, T.L.; Kapnick, S.B.; Murakami, H.; Vecchi, G.A.; Zhang, W. Weakening of the North American monsoon with global warming. Nat. Clim. Chang. 2017, 7, 806-812. [CrossRef]

16. McKenney, D.W.; Hutchinson, M.F.; Papadopol, P.; Lawrence, K.; Pedlar, J.; Campbell, K.; Milewska, E.; Hopkinson, R.F.; Price, D.; Owen, T. Customized spatial climate models for North America. Bull. Am. Meteorol. Soc. 2011, 92, 1611-1622. [CrossRef]

17. Sheppard, P.R.; Comrie, A.C.; Packin, G.D.; Angersbach, K.; Hughes, M.K. The climate of the US Southwest. Clim. Res. 2002, 21, 219-238. [CrossRef]

18. Hutchinson, M.; Xu, T. Anusplin Version 4.4 User Guide; Australia National University: Canberra, Australia, 2013.

19. Marquardt, P.E.; Miranda, B.R.; Telewski, F.W. (2018-01-18): NOAA/WDS Paleoclimatology - Mt. Bigelow - PIAZ, PIPO - ITRDB AZ595-596 [Study 23650-23651]; Mt. Lemmon - PIAZ, PIPO - ITRDB AZ597-598 [Study 23652-23653]. NOAA National Centers for Environmental Information. Available online: https: //www.ncdc.noaa.gov/paleo/study/xxxxx (accessed on 1 October 2018).

20. Cook, E.R. ATime Series Analysis Approach to Tree Ring Standardization. Ph.D. Thesis, University of Arizona, Tucson, AZ, USA, 1985.

21. Bunn, A.G. A dendrochronology program library in R (dplR). Dendrochronologia 2008, 26, 115-124. [CrossRef]

22. Bunn, A.G. Statistical and visual crossdating in R using the dplR library. Dendrochronologia 2010, 28, 251-258. [CrossRef]

23. R Core Team. R: A Language and Environment for Statistical Computing; R Foundation for Statistical Computing: Vienna, Austria, 2016; Available online: https://www.R-project.org/ (accessed on 1 October 2018).

24. Peloquin, R.L. The identification of three-species hybrids in the ponderosa pine complex. Southwest. Nat. 1984, 29, 115-122. [CrossRef]

25. Rehfeldt, G.E. Genetic variation in the Ponderosae of the southwest. Am. J. Bot. 1993, 80, 330-343. [CrossRef]

26. Zang, C.; Biondi, F. Treeclim: An R package for the numerical calibration of proxy-climate relationships. Ecography 2015, 38, 431-436. [CrossRef]

27. Wei, T.; Simko, V. R Package "Corrplot": Visualization of a Correlation Matrix (Version 0.84). 2017. Available online: https://github.com/taiyun/corrplot (accessed on 1 October 2018).

28. Kienast, F.; Luxmoore, R.J. Tree-ring analysis and conifer growth responses to increased atmospheric CO 2 levels. Oecologia 1988, 76, 487-495. [CrossRef] [PubMed] 
29. Lévesque, M.; Rigling, A.; Bugmann, H.; Weber, P.; Brang, P. Growth response of five co-occurring conifers to drought across a wide climatic gradient in Central Europe. Agri. Forest Meteorol. 2014, 197, 1-12. [CrossRef]

30. Kilgore, J. Distribution and Ecophysiology of the Ponderosae in the Santa Catalina Mountains of Southern Arizona. Ph.D. Thesis, Michigan State University, East Lansing, MI, USA, 2007.

31. Norris, J.R.; Jackson, S.T.; Betancourt, J.L. Classification tree and minimum-volume ellipsoid analyses of the distribution of ponderosa pine in the western USA. J. Biogeogr. 2006, 33, 342-360. [CrossRef]

32. Ziaco, E.; Truettner, C.; Biondi, F.; Bullock, S. Moisture-driven xylogenesis in Pinus ponderosa from a Mojave Desert mountain reveals high phenological plasticity. Plant Cell Environ. 2018, 41, 823-836. [CrossRef] [PubMed]

33. Palmer, W.C. Meteorological Drought; U.S. Weather Bureau Research Paper No. 45; US Department of Commerce: Washington, DC, USA, 1965; Volume 30, pp. 1-58.

34. Wilmking, M.; Juday, G.P.; Barber, V.A.; Zald, H.S. Recent climate warming forces contrasting growth responses of white spruce at treeline in Alaska through temperature thresholds. Glob. Chang. Biol. 2004, 10, 1724-1736. [CrossRef]

35. Briffa, K.; Jones, P. Basic Chronology statistics and assessment. In Methods of Dendrochronology; Cook, E.R., Kairiukstis, L.A., Eds.; Springer Science Business Media B.V: Dordrecht, The Netherlands, 1990; pp. 137-152. ISBN 978-90-481-4060-2.

36. Fritts, H.C. Tree Rings and Climate; Academic Press Inc.: London, UK, 1976; ISBN 012 268450-8.

37. Wigley, T.M.L.; Briffa, K.R.; Jones, P.D. On the average value of correlated time series, with applications in dendroclimatology and hydrometeorology. J. Clim. Appl. Meteorol. 1984, 23, 201-213. [CrossRef]

(C) 2019 by the authors. Licensee MDPI, Basel, Switzerland. This article is an open access article distributed under the terms and conditions of the Creative Commons Attribution (CC BY) license (http://creativecommons.org/licenses/by/4.0/). 